\title{
Exhaled Breath Condensate 8-Isoprostane, Clinical Parameters, Radiological Indices and Airway Inflammation in COPD
}

\author{
Demosthenes Makris $^{a}$ Emmanouil Paraskakis ${ }^{a}$ Panos Korakas ${ }^{d}$ \\ Emmanouil Karagiannakis $^{d}$ Giorgos Sourvinos ${ }^{c}$ Nikolaos M. Siafakas ${ }^{a}$ \\ Nikos Tzanakis ${ }^{a, b}$ \\ Departments of a Thoracic Medicine and ${ }^{b}$ Epidemiology, ' Laboratory of Virology, Medical School, \\ University of Crete, and ${ }^{d}$ Department of Radiology, A. Georgios Hospital, Heraklion, Greece
}

\section{Key Words}

COPD $\cdot$ Emphysema $\cdot$ 8-Isoprostane $\cdot$ Sputum induction • Dyspnea

\begin{abstract}
Background: Exhaled breath condensate (EBC) 8-isoprostane levels were found increased in chronic obstructive pulmonary disease. However, the relation between EBC 8-isoprostane and parameters which have a known predictive value in COPD, remains vastly unknown, and so does subsequently its clinical value. Objectives: To investigate the relationship between 8-isoprostane level in EBC and clinical parameters, radiological indices and airway inflammation in COPD patients. Materials and Methods: We studied 18 COPD patients (all ex-smokers) and 12 healthy controls (5 exsmokers and 7 never-smokers). All patients underwent clinical evaluation, sputum induction, high-resolution computed tomography (HRCT) of the thorax and EBC 8-isoprostane measurement. 8-Isoprostane levels were correlated with markers that reflect disease severity, such as dyspnea severity, $\mathrm{FEV}_{1}$ (\%pred), emphysema changes and bronchiectasis in HRCT. Emphysema was quantified as the percentage of lung area with attenuation values $<-950$ Hounsfield units.
\end{abstract}

Results: 8-Isoprostane levels were significantly elevated in EBC of patients with COPD [mean (SE) 18.1 (2) vs. $5.6(0.7) \mathrm{pg} /$ $\mathrm{ml}, \mathrm{p}=0.0001]$, irrespective of lung function impairment. 8Isoprostane levels were correlated with emphysema score in HRCT ( $\left.r^{2}=0.43, p=0.001\right)$ as well as with Medical Research Council dyspnea scale score ( $r h o=0.61, p=0.005$ ). Conclusion: Our findings suggest that EBC 8-isoprostane levels may reflect the extension of lung emphysema in COPD patients. In this respect, further investigation is required in order to evaluate the possible role of EBC 8-isoprostane in assessing disease progress in COPD patients.

Copyright $\odot 2007$ S. Karger AG, Basel

\section{Introduction}

Airway inflammation has a central role in the development and progression of COPD [1]. A growing body of evidence showed that increased oxidative stress is an important pathway of the underlying pathophysiology of airway and lung parenchyma inflammation in COPD patients [2], particularly in smokers [3]. The presence of unbalanced oxidative stress has been related to increased expression of proinflammatory mediators, downregula-

\section{KARGER}

Fax +4161306 1234 E-Mail karger@karger.ch www.karger.com
(C) 2007 S. Karger AG, Basel

0025-7931/08/0752-0138\$24.50/0

Accessible online at:

www.karger.com/res
D.A. Makris, MD

Department of Thoracic Medicine, Albert Calmette University Hospital

Bvd Pr. Jules Leclercq

FR-59037 Lille Cedex (France)

E-Mail appollon7@hotmail.com 
tion of relevant anti-inflammatory genes, increased sequestration of neutrophils in the pulmonary microvasculature, inactivation of antiproteinases, epithelial injury and mucus hypersecretion [4]. The sources of the increased oxidative stress in COPD derive either from inhaled oxidants or/and from the increased amounts of reactive oxygen species, generated by inflammatory and structural cells involved in the pathophysiology of the disease [5].

The detection and measurement of lipid peroxidation products established the involvement of free-radical reactions in the disease [6]. Peroxidation of lipids produces bioactive prostaglandin F2-like compounds, fairly stable at physiological temperatures, which can serve as noninvasive makers of the increased oxidant burden [6]. Among products of lipid peroxidation, exhaled breath condensate (EBC) 8-isoprostane levels were found increased in both stable COPD [7, 8] and exacerbations [9]. However, the relationship of this marker with parameters which have a known predictive value in COPD and, therefore, its clinical value remain largely unknown $[8,10,11]$.

The primary aim of the present study was to evaluate the concentrations of 8-isoprostane in EBC of patients with stable COPD and to investigate whether there is any relationship between 8 -isoprostane levels and main parameters of the disease such as symptoms, stage of severity, emphysematous changes and airway inflammation.

\section{Methods}

\section{Subjects}

Thirty subjects were prospectively studied: 18 patients with COPD (ex-smokers), and 12 healthy individuals (5 ex-smokers and 7 never-smokers). COPD patients were recruited from the outpatient clinic of Agios Georgios Hospital of Crete, according to the GOLD criteria [1]. According to the GOLD severity of COPD, 7 (38.8\%) patients were stage II, 5 (27.7\%) were stage III, $6(33.3 \%)$ were stage IV. At baseline, history of respiratory symptoms was taken in detail, dyspnea was assessed by the Medical Research Council (MRC) scale and 6MWT was performed as previously described [12] according to standardized guidelines [13]. Subjects with a history of asthma, allergic rhinitis, atopy, or other respiratory disease were excluded from the study. None of the patients had exacerbations for at least 4 weeks preceding the study, and none had received antibiotics or oral and inhaled corticosteroids over the same period. After initial evaluation, subjects underwent on separate days EBC 8-isoprostane measurement and sputum induction for assessment of airway inflammation. In addition, all 18 patients underwent high-resolution computed tomography (HRCT) of the thorax for emphysema assessment. The study was approved by the ethics committee of the local health authority and the patients provided written informed consent.
Dyspnea Assessment

The modified MRC dyspnea scale was used [14]. This is scored on a 5 -point scale from 0 to 4 , where grade 0 describes the subject as 'not troubled by shortness of breath except with strenuous exercise', and grade 4 describes the subject as 'too breathless to leave the house or breathless when dressing or undressing'.

The 6MWT was performed as previously described [12]. Briefly, the test was performed indoors at about the same time of day, along a 100 -feet flat, straight hallway. The walking course was $30 \mathrm{~m}$ in length and it was marked every $3 \mathrm{~m}$. Instructions to patients were given according to accepted recommendations [13]. The patient should sit at rest in a chair, located near the starting position, for at least $10 \mathrm{~min}$ before the test started. A physician should stand near the starting line during the test without walking with the patient. Only the standardized phrases for encouragement [13] were used during the test. When the test was finished, the laps from the counter and additional distance covered were recorded.

Spirometry

Postbronchodilation spirometry was performed following premedication with $200 \mu \mathrm{g}$ salbutamol via metered-dose inhaler, using a computerized system (Lab 2.12; Jaeger; Würzburg, Germany) [15].

\section{Sputum Induction}

A previously described procedure was followed for sputum induction, processing, total cell counting, and differential cell counting [16]. Briefly, sputum was induced via inhalation of a hypertonic saline solution aerosol, generated by an ultrasonic nebulizer (Ultraneb 2000; DeVilbiss; Somerset, Pa., USA) as previously described. The viscid portions of the expectorated sample were separated from the sputum and processed within 15 min after termination of the induction. The weight of the plugs was determined, and dithiothreitol 0.1\% (Sputolysin; Calbiochem; La Jolla, Calif., USA) in phosphate-buffered saline solution was added at a ratio of $2 \mathrm{ml}$ to $1 \mathrm{~g}$ of the sputum plugs. The samples were agitated on a vortex mixer and placed in a shaking water bath to ensure complete homogenization. Subsequently, RPMI-1640 plus $10 \%$ fetal calf serum was added in a volume twice that of the homogenized sample and samples were filtered through 48- $\mu$ m nylon gauze (Thompson, Canada). A total cell count of the filtered sample was performed and viability was tested by means of the trypan blue exclusion staining (Sigma-Aldrich Corporation, St. Louis, Mo., USA) in a Neubauer hemacytometer. The suspension was then centrifuged at $400 \mathrm{~g}$ for $5 \mathrm{~min}$, and the pellet was resuspended with RPMI-1640 and 10\% fetal calf serum. The samples were adjusted to a concentration of $0.35 \times 10^{6}$ cells per milliliter and $50 \mu \mathrm{l}$ of the cell suspension was centrifuged by an aerospray cytocentrifuge (Wescor; Claremont, Canada) at 300 revolutions per minute with low deceleration for $5 \mathrm{~min}$. Five hundred nonsquamous cells in coded May-Giemsa-Grunwald cytospins were counted in a blinded fashion by 2 independent investigators and averaged. Cell differential counts were expressed as percentage of nonsquamous cells and as absolute number of cells per gram of selected sputum sample. Absolute cell numbers were calculated by multiplying the cell percentage by the total (nonsquamous) cell number in the sputum, divided by the weight of the selected sputum sample. 


\section{Radiological Indexes}

Patients underwent high-resolution CT of the thorax with a scanner (Hi-Speed Advantage, GE Medical Systems, Milwaukee, Wisc., USA), in the supine position. Scanning parameters included collimation of $1 \mathrm{~mm}$, section interval of $10 \mathrm{~mm}, 120 \mathrm{kV}$, and $220 \mathrm{~mA}$. Expiratory scans were obtained in all patients by using similar parameters. Images were reconstructed into a bone algorithm, and films were obtained by using standard lung window settings (window level, -700 Hounsfield units, HU; window width, 1,000-1,500 HU). Emphysema was quantified as the relative (\%) of lung area occupied by pixels with attenuation values lower than $-950 \mathrm{HU}[17,18]$

Bronchiectasis was quantified as it has been previously suggested [16]. Briefly, we first assessed the extent assigning a score to each of the lobes according to the percentage of lobar involvement. We used the following scale: grade 0 (none); grade $1(<25 \%)$ grade 2 (25-50\%), and grade 3 (>50\% involvement of each lobe). Finally, all individual lobar scores were summed to calculate the overall score for the extent of bronchiectasis. In addition, we evaluated the thickness of the bronchial wall in relation to the external diameter of dilated bronchi (EDDB) perpendicular to the transverse plane. We used the following scale: grade 0 , normal thickness; grade 1 , thickness $>20 \%$ and $<50 \%$ EDDB; grade $2>50 \%$ EDDB; and grade 3, complete obliteration of the bronchial lumen. A mean score was calculated per lobe and the sum of individual lobar bronchial wall thickening scores was the overall score for each patient [19]. The images were read in random order by a thoracic radiologist (P.K.) and were read again 6 weeks after initial evaluation. The radiologist was blinded to the initial evaluation score to test for intraobserver variation. Interobserver error was tested as follows: a second radiologist (E.K.), who was blinded to the initial scores, independently evaluated all high-resolution CT images. Any differences were resolved by consensus.

\section{EBC and 8-Isoprostane Measurements}

EBC was collected as previously described [20] following the standardized recommendations and assessed for repeatability and stability $[11,20]$. Briefly, EBC was collected using a specially designed double-jacketed glass tube. The tube had an internal/external diameter of $4 / 7 \mathrm{~cm}$, respectively, a length of $45 \mathrm{~cm}$ and was adapted to a heat exchanger unit (RHES, Jaeger); thus, the tube was cooled by air (cold air of $-20^{\circ} \mathrm{C}$, airflow of $80 \mathrm{l} / \mathrm{min}$ ). At the proximal end of the tube, a two-way unidirectional valve separated inspiration from expiration. Subjects, after rinsing their mouths, breathed tidally through a mouthpiece connected to the condensing chamber for $10 \mathrm{~min}$, while using noseclips. One $\mathrm{ml}$ of breath condensate was collected at the distal end of the tube and stored at $-70^{\circ} \mathrm{C}$ in a $2-\mathrm{ml}$ sterile plastic tube. In order to avoid gross salivary contamination, a saliva trap was used, and the condenser was placed at a higher level than the mouth, making it more unlikely that saliva can enter the collecting device. The repeatability of 8 -isoprostane measurements and the stability of the frozen samples were estimated in 5 control subjects and 8 patients with COPD. Repeatability was assessed by measuring 8 -isoprostane in EBC collected on 2 consecutive days under same conditions. For stability assessment, 8 -isoprostane concentrations were determined after different storage periods ( 2 days, 3 weeks and 2 months). To perform these measurements, collected EBC was divided in equal samples and stored in different $2-\mathrm{ml}$ sterile plastic tubes. 8 -Isoprostane concentration was determined by a compet-
Table 1. Clinical data of COPD patients and controls

\begin{tabular}{lcc}
\hline & $\begin{array}{c}\text { COPD } \\
(\mathrm{n}=18)\end{array}$ & $\begin{array}{l}\text { Controls } \\
(\mathrm{n}=12)\end{array}$ \\
\hline Age, years & $64(2)$ & $61(3.5)$ \\
$\mathrm{Male}_{\text {female }}$ & $6 / 12$ & $3 / 9$ \\
$\mathrm{FEV}_{1}$, ml & $1,395(150)$ & $1,550(230)$ \\
$\mathrm{FEV}_{1}, \%$ pred & $47(5)$ & $94(5)$ \\
$\mathrm{FEV}_{1} /$ FVC $(\%)$ & $59(2)$ & $90(3)$ \\
$\mathrm{COPD}$ severity (GOLD), $\mathrm{n}(\%)$ & & $\mathrm{n} / \mathrm{a}$ \\
$\quad$ Stage II & $7(38.3)$ & $\mathrm{n} / \mathrm{a}$ \\
$\quad$ Stage III & $5(27.7)$ & $\mathrm{n} / \mathrm{a}$ \\
$\quad$ Stage IV & $6(33.3)$ & $96(0.5)$ \\
SpO & $\%$ \\
MRC score (range) & $92(1)$ & $0(0-1)$ \\
6MWT, m & $1(1-3)$ & $590(35)$ \\
Chronic cough, $\mathrm{n}(\%)$ & $320(28)$ & - \\
Chronic sputum, $\mathrm{n}(\%)$ & $6(50)$ & - \\
\hline
\end{tabular}

Data are presented as mean (SE) unless otherwise indicated.

itive enzyme immunoassay kit (Cayman Chemical, Ann Arbor, Mich., USA), previously tested for its utility to assess 8-isoprostane in EBC [7]. The detection limit of the assay was $4 \mathrm{pg} / \mathrm{ml}$.

\section{Statistical Analysis}

The results are shown as mean (SE) values or median (range) values for continuous data and as n (\%) for categorical data unless otherwise indicated. Differences between patients were explored using Student's t test for quantitative, normally distributed variables or, if not applicable, with the nonparametric Wilcoxon signed rank test for paired data, and the Mann-Whitney test for unpaired data, or Fisher's exact test for qualitative variables. Correlations between 8 -isoprostane and normally distributed variables were assessed by Pearson's $r$ and non-normally distributed variables by Spearman's rho. A p value of $<0.05$ was considered significant, and the SPSS for Windows 13 (SPSS Inc., Chicago Ill., USA) was used for the analysis.

\section{Results}

Clinical data of healthy subjects and patients with COPD are summarized in table 1 . All patients were exsmokers, mean (SE) pack-years 45 (5); 5 controls were exsmokers, 50 (5) pack-years, and 7 controls were neversmokers. All but 2 subjects (1 patient and 1 control) enrolled in the study produced adequate sputum samples with a mean (SE) percentage viability 92.4 (9) and squamous cell contamination 15.5 (11). The viability of the cells (percentage of total) in induced sputum did not differ between COPD patients and controls. The total cell count $\left(\times 10^{7}\right.$ cells per $\left.\mathrm{g}\right)$ median (range), $5.4(1.7-8)$ was 


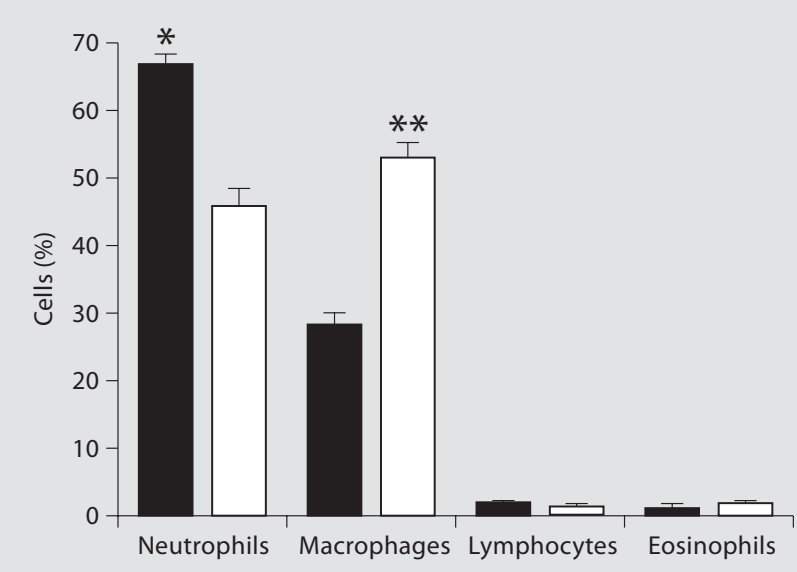

Fig. 1. Sputum differential cell counts in healthy controls ( $\square$ ) and patients with $\operatorname{COPD}(\square) ;{ }^{*} \mathrm{p}=0.005,{ }^{* *} \mathrm{p}=0.001$. Bars represent mean values with standard errors.

significantly higher in patients than in control subjects [1.0 (0.3-2.0), $\mathrm{p}=0.0001]$. The percentage of neutrophils was significantly higher in COPD patients compared to controls $(p=0.005)$, and a significantly lower percentage of macrophages was found in patients with COPD compared to controls (fig. 1).

\section{HRCT Findings}

HRCT quantitative analysis was successfully performed in all COPD patients. The extent of emphysema, expressed as relative lung area with CT number $<950$ HU, was mean (SE) 40 (5)\% of total lung cross-sectional area (range $1-70 \%$ ). Five of 18 patients (28\%) had significant detectable bronchiectasis (total bronchiectasis score $\geq 2$ ). Bronchial wall thickening score was $3(0.2)$.

\section{EBC 8-Isoprostane}

$\mathrm{EBC}$ was collected in all cases. The mean (SE) volume of EBC collected was 1.19 (0.05) $\mathrm{ml}$. The duration of collection was 21.5 (1) min. The measurements of EBC 8isoprostane in the same subject on consecutive days were repeatable. In COPD patients, the respective values were $16.5(2.5)$ and $17.7(2.2)(\mathrm{p}=0.5)$ and in controls they were $5.1(0.9)$ and $6.2(0.8)(\mathrm{p}=0.6)$, respectively. EBC 8-isoprostane $(\mathrm{pg} / \mathrm{ml})$ in frozen samples after 2 days, 3 weeks and 2 months of storage were 13.4 (2.2), 11.9 (2.2) and 12.7 (2.4), respectively ( $\mathrm{p}<0.05)$.

The respective values of 8 -isoprostane measurements (pg/ml) were as follows: COPD patients vs. controls, 18.1

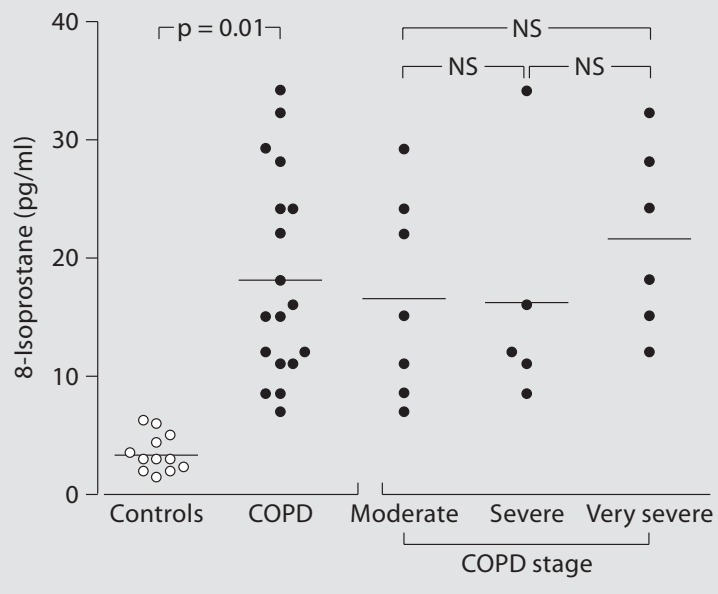

Fig. 2. 8-Isoprostane concentrations in breath condensate in controls $(\bigcirc)$ and in COPD patients $(\mathbf{O})$ taken as entire group and according to disease severity. Horizontal bars represent mean values.

(2) vs. 5.6 (0.7), p = 0.0001. There were no significant differences between the different stages according to GOLD staging of COPD severity (fig. 2). The values of 8 -isoprostane $(\mathrm{pg} / \mathrm{ml})$ for patients of GOLD stage II were 16.6 (3), for stage III 16.1 (4.5) and for stage IV 21.5 (3), respectively.

\section{Relationship between 8-Isoprostane and Clinical, \\ HRCT Parameters, Induced Sputum Cells}

In patients with COPD, there was a significant correlation between 8-isoprostane values and MRC dyspnea score, rho $=0.61, \mathrm{p}=0.005$ (fig. 3). A significant correlation was also found between 8 -isoprostane levels and the extent of emphysema, $\mathrm{r}^{2}=0.43, \mathrm{p}=0.001$ (fig. 4). The median (range) 8 -isoprostane value $(\mathrm{pg} / \mathrm{ml})$ for patients with total bronchiectasis score $\geq 2$ was 16 (15-22), whereas for patients with total bronchiectasis score $<2$ it was 15 (734) $(\mathrm{p}=0.8)$. No significant correlation was found between EBC 8-isoprostane values and $\mathrm{FEV}_{1} \%$ pred. of COPD subjects $(\mathrm{p}=0.4)$. No significant association was found between 8-isoprostane values of COPD patients and sputum cell counts.

\section{Discussion}

In the present study, we found that 8-isoprostane levels are elevated in the EBC of patients with COPD, irrespective of lung function impairment. Despite the fact that 


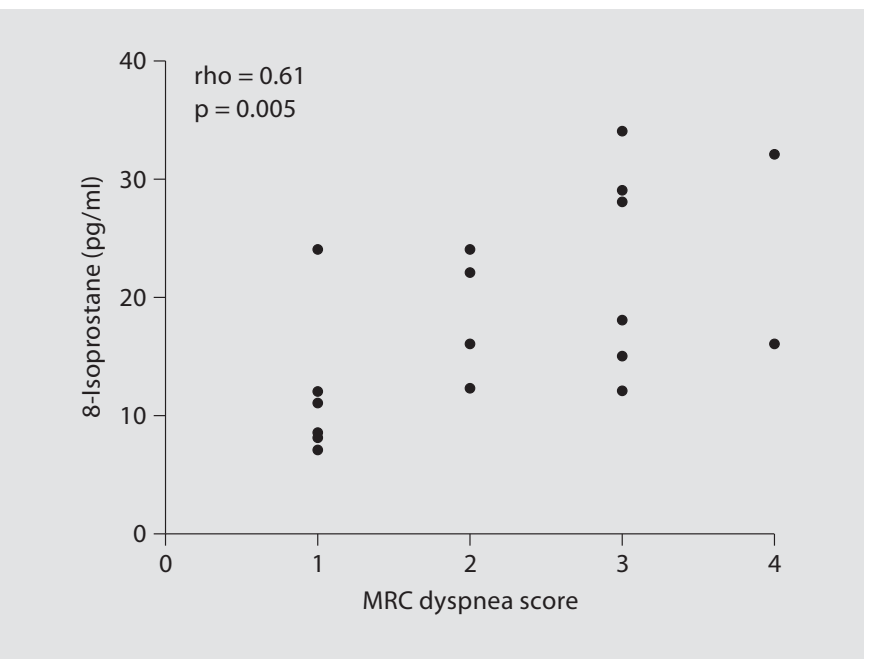

Fig. 3. Correlation between MRC dyspnea scale values and 8-isoprostane concentrations in the expired breath condensate of COPD patients.

EBC 8-isoprostane was not found to be correlated with most of the clinical variables used in this study, we found a significant correlation between 8-isoprostane levels and the extent of emphysema as measured by HRCT and MRC dyspnea. These findings are novel since there are no data for the relationship of EBC 8-isoprostane with main clinical parameters in COPD but for the severity stages. In this respect, since 8-isoprostane is a relatively stable marker of oxidative stress, its measurement in EBC may have clinical importance as a noninvasive biomarker of the underlying inflammatory process in COPD.

This is the first investigation which has estimated the relationship between 8 -isoprostane and emphysema. We assessed emphysema score by HRCT using the $-950 \mathrm{HU}$ threshold which reflects the microscopic emphysema [17] and the reduction of CO diffusion [18]. We found a significant correlation between 8-isoprostane levels and extent of HRCT emphysema in patients with COPD, which suggests an association between oxidant burden and parenchymal changes [21,22]. Unbalanced oxidative stress may have either a direct effect on target cells in the airways via the formation of oxidized mediators such the ROS, isoprostanes and hydroxyl-nonenal, or an indirect effect via activation of signal transduction pathways, transcription factors $[4,23]$ or via apoptosis [24]. On this basis, the significant correlation between EBC 8-isoprostane and emphysema found in this study may reflect the undergoing inflammatory process in the lung parenchyma and it may contribute to the understanding of the

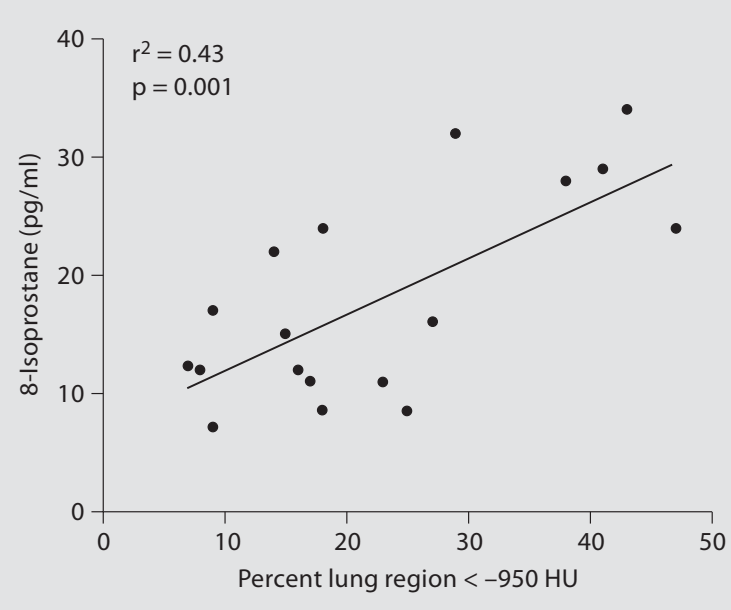

Fig. 4. Correlation between emphysema in HRCT and 8-isoprostane concentrations in the expired breath condensate of COPD patients.

pathophysiology in COPD. Furthermore, our findings suggest that the measurement of 8-isoprostane in EBC may have the potential to reflect emphysema changes in COPD patients and thus, disease progress.

In contrast, we could not demonstrate any relationship between the levels of 8 -isoprostane and the coexisting moderate bronchiectasis and bronchial thickening as quantified by HRCT in our patients. Thus, bronchiectasis might have not contributed substantially to the significantly increased 8-isoprostane levels found in our patients. Previous studies $[10,25]$ have reported increased oxidative stress in patients with a clinical and radiological diagnosis of bronchiectasis. However, coexisting bronchiectasis is moderate in COPD patients [26] and there is no evidence yet that such a moderate coexisting disorder could affect significantly the levels of 8-isoprostane or of other markers of oxidative stress in COPD patients, although this could be possible.

In this study, we assessed the clinical severity of COPD using respiratory symptoms and $\mathrm{FEV}_{1}$. We found that 8isoprostane levels were significantly associated with dyspnea on the MRC scale. The MRC dyspnea scale is a simple and valid method to categorize patients with COPD in terms of their disability and could be used to complement $\mathrm{FEV}_{1}$ in the diagnosis and classification of COPD severity [27]. Thus, the correlation found between dyspnea and 8-isoprostane suggests also potential utility of EBC measurements in assessing symptom severity and health status of COPD patients. Based on our findings, it 
would be of interest to assess in the future the predictive value of 8 -isoprostane in the response of COPD patients to treatment targeting dyspnea relief [28].

In accordance with a previous study $[7,8]$, we could not show any significant association between EBC 8-isoprostane and lung function impairment. An explanation to that could be that $\mathrm{FEV}_{1}$ and 8 -isoprostane are two different markers in the complicated pathophysiology of COPD. Whereas $\mathrm{FEV}_{1}$ reflects broadly airway caliber and lung mechanics, 8-isoprostane is a product of lipid peroxidation reflecting oxidative stress which can be present even without severe airflow limitation $[4,7,8]$.

In the present study, we demonstrated the neutrophilic inflammation in induced sputum that is a well-established inflammatory process in COPD. However, we found no relationship between airway neutrophilia and oxidative stress by measuring 8 -isoprostane in EBC. This is in agreement with the results of a previous investigation in COPD [10]. A plausible explanation for this dissociation is that sputum neutrophilia reflects inflammation in central airways but not in small airways and alveoli $[29,30]$, whereas 8 -isoprostane EBC levels assess inflammation in the whole lung. Increased 8-isoprostane EBC levels were found both in airway $[7,10,31]$ and in lung parenchymal diseases [22]. The significant correlation between 8-isoprostane and emphysema in HRCT which was found in our study supports this hypothesis.

In this investigation, our methodology for collecting or processing breath condensate was based on previously reported methods $[7,10]$. The finding of increased levels of 8-isoprostane observed in this study using a competitive enzyme immunoassay is in agreement with several earlier studies which have assessed this marker in the EBC of COPD patients [7-9]. However, there are a number of uncertainties regarding the usefulness and standardization of the oxidative stress marker assessment in EBC $[11,32,33]$. In this respect, it should be acknowledged that despite the useful information that enzyme immunoassay of 8-isoprostane provides, still more specific and sensitive assays are required.
The levels of 8-isoprostane measured in this study in COPD patients (ex-smokers) were similar to some of the previous studies $[9,23]$ and lower than others $[7,9]$. This suggests that EBC 8-isoprostane values in different investigations vary but the difference between patients and controls is a constant finding. This discrepancy at the absolute values from the various studies could not be easily explained. Many factors may affect the assay of 8-isoprostane of different populations. Since normal values are not found yet for 8-isoprostane in EBC, we believe it is difficult to compare absolute values from different historical studies.

It should also be noted that a direct examination of EBC for saliva was not performed in this study because our design for EBC collection made saliva contamination of EBC unlike. Previous studies demonstrated that if care is taken to exclude saliva from EBC samples, amylase can be detected only in a small portion of samples with levels approximately 10,000 times lower that those in saliva [34]. In addition, amylase measurements are not specific for salivary amylase and amylase can also be found in the lungs, so positive results of the test do not necessarily mean salivary contamination. Thus, following recent recommendations we have not performed salivary amylase assessment since appropriate precautions for salivary contamination have been taken [11].

In conclusion, this study confirms that COPD patients have increased levels of 8-isoprostane in $\mathrm{EBC}$, irrespective of lung function impairment. Notably, we found that 8 -isoprostane EBC levels are significantly correlated with the extent of emphysema, as measured by HRCT, and with dyspnea. This observation suggests that EBC 8-isoprostane could be a useful, noninvasive diagnostic tool that may reflect important clinical outcomes in COPD. However, further investigation is required to study EBC 8 -isoprostane cellular source, its precise role in COPD pathogenesis and most importantly, whether there is any role for this biomarker in following emphysematous changes and response to treatment targeting dyspnea in COPD patients.

\section{References}

1 Celli BR, MacNee W: ATS/ERS Task Force. Standards for the diagnosis and treatment of patients with COPD: a summary of the ATS/ ERS position paper. Eur Respir J 2004;23: 932-946.

8-Isoprostane and Emphysema in COPD
2 Dekhuijzen PNR, Aben KKH, Dekker I, Aarts LPHJ, Wielders PLML, van Heerwarden CLA, Bast A: Increased exhalation of hydrogen peroxide in patients with stable and unstable chronic obstructive pulmonary disease. Am J Respir Crit Care Med 1996; 154:813-816.
3 Maestrelli P, El Messlemani AH, De Fina O, Nowicki Y, Saetta M, Mapp C, Fabbri LM: Increased expression of heme oxygenase (HO)-1 in alveolar spaces and HO-2 in alveolar walls of smokers. Am J Respir Crit Care Med 2001;15:1508-1513. 
-4 Barnes PJ, Shapiro SD, Pauwels RA: Chronic obstructive pulmonary disease: molecular and cellular mechanisms. Eur Respir J 2003; 22:672-688.

5 Rahman I, Gilmour PS, Jimenez LA, MacNee W: Oxidative stress and TNF-alpha induce histone acetylationand NF-kappaB/ AP-1 activation in alveolar epithelial cells: potential mechanism in gene transcription in lung inflammation. Mol Cell Biochem 2002;234-235:239-248.

6 Gutteridge GM: Lipid peroxidation and antioxidants as biomarkers of tissue damage. Clin Chem 1995;41:1819-1828.

$\checkmark 7$ Montuschi P, Collins JV, Ciabattoni G, Lazzeri N, Corradi M, Kharitonov SA, Barnes PJ: Exhaled 8-isoprostane as an in vivo biomarker of lung oxidative stress in patients with COPD and healthy smokers. Am J Respir Crit Care Med 2000;162:1175-1177.

8 Kostikas K, Papatheodorou G, Psathakis K, Panagou P, Loukides S: Oxidative stress in expired breath condensate of patients with COPD. Chest 2003;124:1373-1380.

$\checkmark 9$ Biernacki WA, Kharitonov SA, Barnes PJ: Increased leukotriene B4 and 8-isoprostane in exhaled breath condensate of patients with exacerbations of COPD. Thorax 2003;58: 294-298.

10 Kostikas K, Papatheodorou G, Ganas K, Psathakis K, Panagou P, Loukides S: pH in expired breath condensate of patients with inflammatory airway diseases. Am J Respir Crit Care Med 2002;15:165:1364-1370.

-11 Horvath I, Hunt J, Barnes PJ, Alving K, Antczak A, Baraldi E, Becher G, van Beurden WJ, Corradi M, Dekhuijzen R, Dweik RA, Dwyer T, Effros R, Erzurum S, Gaston B, Gessner C, Greening A, Ho LP, Hohlfeld J, Jobsis Q, Laskowski D, Loukides S, Marlin D, Montuschi $\mathrm{P}$, Olin AC, Redington AE, Reinhold P, van Rensen EL, Rubinstein I, Silkoff P, Toren K, Vass G, Vogelberg C, Wirtz H; ATS/ERS Task Force on Exhaled Breath Condensate: Exhaled breath condensate: methodological recommendations and unresolved questions. Eur Respir J 2005;26:523-548.

-12 Makris D, Tzanakis N, Moschandreas J, Siafakas NM: Dyspnea assessment and adverse events during sputum induction in COPD. BMC Pulm Med 2006;6:17.

13 American Thoracic Society (ATS): ATS statement: guidelines for the six-minute walk test. Am J Respir Crit Care Med 2002; 166:111-117.
14 Martinez JA, Straccia L, Sobrani E, Silva GA, Vianna EO, Filho JT: Dyspnea scales in the assessment of illiterate patients with chronic obstructive pulmonary disease. Am J Med Sci 2000;320:240-243.

15 American Thoracic Society: Standardization of Spirometry, 1994 Update. Am J Respir Crit Care Med 1995;152:1107-1136.

16 Tsiligianni J, Tzanakis N, Kyriakou D, Chrysofakis G, Siafakas N, Bouros D: Comparison of sputum induction with bronchoalveolar lavage cell differential counts in patients with sarcoidosis. Sarcoidosis Vasc Diffuse Lung Dis 2002;19:205-210

17 Gevenois PA, De Vuyst P, de Maertelaer V, Zanen J, Jacobovitz D, Cosio MG, Yernault JC: Comparison of computed density and microscopic morphometry in pulmonary emphysema. Am J Respir Crit Care Med 1996;154:187-192.

18 Baldi S, Miniati M, Bellina CR, Battolla L, Catapano G, Begliomini E, Giustini D, Giuntini C: Relationship between extent of pulmonary emphysema by high-resolution computed tomography and lung elastic recoil inpatients with chronic obstructive pulmonary disease. Am J Respir Crit Care Med 2001;164:585-589.

19 Ooi GC, Khong PL, Chan-Yeung M, Ho JCM, Chan PKS, Lee JCK, Lam WK, Tsang KWT: High-resolution CT quantification of bronchiectasis: clinical and functional correlation. Radiology 2002;225:663-672.

-20 Psathakis K, Papatheodorou G, Plataki M, Panagou P, Loukides S, Siafakas NM, Bouros D: 8-Isoprostane, a marker of oxidative stress, is increased in the expired breath condensate of patients with pulmonary sarcoidosis. Chest 2004;125:1005-1011.

-21 Carpenter CT, Price PV, Christman BW: Exhaled breath condensate isoprostanes are elevated in patients with acute lung injury or ARDS. Chest 1998;114:1653-1659.

22 Montuschi P, Ciabattoni G, Paredi P, Pantelidis $\mathrm{P}$, du Bois RM, Kharitonov SA, Barnes PJ: 8-Isoprostane as a biomarker of oxidative stress in interstitial lung diseases. Am J Respir Crit Care Med 1998;158:1524-1527.

23 Carpagnano GE, Kharitonov SA, FoschinoBarbaro MP, Resta O, Gramiccioni E, Barnes PJ: Supplementary oxygen in healthy subjects and those with COPD increases oxidative stress and airway inflammation. Thorax 2004;59:1016-1019.

24 Tuder RM, Zhen L, Cho CY, TarasevicieneStewart L, Kasahara Y, Salvemini D, Voelkel NF, Flores SC: Oxidative stress and apoptosis interact and cause emphysema due to vascular endothelial growth factor receptor blockade. Am J Respir Cell Mol Biol 2003;29:8897.
25 Wood LG, Garg ML, Simpson JL, Mori TA, Croft KD, Wark PA, Gibson PG: Induced sputum 8-isoprostane concentrations in inflammatory airway diseases. Am J Respir Crit Care Med 2005;171:426-430.

-26 Patel IS, Vlahos I, Wilkinson TM, LloydOwen SJ, Donaldson GC, Wilks M, Reznek RH, Wedzicha JA: Bronchiectasis, exacerbation indices, and inflammation in chronic obstructive pulmonary disease. Am J Respir Crit Care Med 2004;170:400-407.

$\checkmark 27$ Price DB, Tinkelman DG, Halbert RJ, Nordyke RJ, Isonaka S, Nonikov D, Juniper EF, Freeman D, Hausen T, Levy ML, Ostrem A, van der Molen T, van Schayck CP: SymptomBased Questionnaire for Identifying COPD in Smokers. Respiration 2006;73:285-295.

28 Barnes PJ: Future Advances in COPD Therapy. Respiration 2001;68:441-448.

29 Celli BR, Cote CG, Marin JM, Casanova C, Montes de Oca M, Mendez RA, Pinto Plata V, Cabral HJ: The body-mass index, airflow obstruction, dyspnea, and exercise capacity index in chronic obstructive pulmonary disease. N Engl J Med 2004;350:1005-1012.

-30 Eltayara L, Becklake MR, Volta CA, MilicEmili J: Relationship between chronic dyspnea and expiratory flow limitation in patients with chronic obstructive pulmonary disease. Am J Respir Crit Care Med 1996; 154:1726-1734.

-31 Ekberg-Aronsson M, Pehrsson K, Nilsson JA, Nilsson PM, Lofdahl CG: Mortality in GOLD stages of COPD and its dependence on symptoms of chronic bronchitis. Respir Res 2005;25:98.

32 Alexis NE, Hu SC, Zeman K: Induced sputum derives from the central airways: confirmation using a radiolabeled aerosol bolus delivery technique. Am J Respir Crit Care Med 2001;164:1964-1970.

-33 O’Donnell RA, Peebles C, Ward JA, Daraker A, Angco G, Broberg P, Pierrou S, Lund J, Holgate ST, Davies DE, Delany DJ, Wilson SJ, Djukanovic R: Relationship between peripheral airway dysfunction, airway obstruction, and neutrophilic inflammation in COPD. Thorax 2004;59:837-842.

-34 Antczak A, Kharitonov SA, Montuschi P, Gorski P, Barnes PJ: Inflammatory response to sputum induction measured by exhaled markers. Respiration 2005;72:594-599. 